\title{
Effect of maximum ventilation on abdominal muscle relaxation rate
}

\author{
Dimitris Kyroussis, Gary H Mills, Michael I Polkey, Carl-Hugo Hamnegard, \\ Simon Wragg, Jeremy Road, Malcolm Green, John Moxham
}

\begin{abstract}
Background - When the demand placed on the respiratory system is increased, the abdominal muscles become vigorously active to achieve expiration and facilitate subsequent inspiration. Abdominal muscle function could limit ventilatory capacity and a method to detect abdominal muscle fatigue would be of value. The maximum relaxation rate (MRR) of skeletal muscle has been used as an early index of the onset of the fatiguing process and precedes failure of force generation. The aim of this study was to measure MRR of abdominal muscles and to investigate whether it slows after maximum isocapnic ventilation (MIV).
\end{abstract}

Methods - Five normal subjects were studied. Each performed short sharp expiratory efforts against a $3 \mathrm{~mm}$ orifice before and immediately after a two minute MIV. Gastric pressure (PGA) was recorded and MRR (\% pressure fall $10 \mathrm{~ms}$ ) for each PGA trace was determined.

Results - Before MIV the mean (SD) maximum PGA MRR for the five subjects was $7 \cdot 1(0 \cdot 8) \%$ peak pressure fall $10 \mathrm{~ms}$. Following MIV mean PGA MRR was decreased by $30 \%$ (range $25-35 \%$ ), returning to control values within 5-10 minutes.

Conclusions - The MRR of the abdominal muscles, measured from PGA, is numerically similar to that described for the diaphragm and other skeletal muscles. After two minutes of maximal isocapnic ventilation abdominal muscle $M R R$ slows, indicating that these muscles are sufficiently heavily loaded to initiate the fatiguing process.

(Thorax 1996;51:510-515)

Keywords: respiratory muscle fatigue, abdominal muscles, maximum relaxation rate.

College Hospitals,

London, UK

D Kyroussis

G H Mills

M I Polkey

C-H Hamnegard

S Wragg

J Road

M Green

J Moxham

Correspondence to: Dr D Kyroussis, Respiratory Muscle Laboratory (South Block), Royal Brompton Hospital, London SW3 6NP, UK.

Received 27 March 1995 Returned to authors 6 September 1995 Revised version received 6 November 1995 Accepted for publication 15 December 1995

Abdominal muscles are the principal muscles of expiration. In normal subjects abdominal muscles do not usually contract during quiet breathing. ${ }^{12}$ When the demand placed on the diaphragm and the other inspiratory muscles increases, a rhythmic expiratory contraction of the abdominal muscles is observed. ${ }^{3}$ It is thought that recruitment of abdominal muscle assists diaphragm and inspiratory muscle function. ${ }^{4}$

In normal subjects during resistive breathing and maximum isocapnic ventilation (MIV) inspiratory muscle fatigue can occur in terms of a fall in twitch transdiaphragmatic pressure (TwPDI) or slowing of the maximum relaxation rate (MRR) of the inspiratory muscles..$^{5-8}$ In mechanically ventilated patients who fail to wean, slowing of inspiratory muscle MRR has been demonstrated. ${ }^{9}$ When the respiratory muscles are excessively loaded the role of abdominal muscles could be equally critical. The abdominal muscles are recruited during MIV, resistive breathing, $\mathrm{CO}_{2}$ rebreathing, and heavy exercise in normal subjects. In patients with chronic obstructive pulmonary disease (COPD) abdominal muscle use is prominent during exercise. ${ }^{1011} \mathrm{~A}$ method to detect the possibility of abdominal muscle fatigue in circumstances in which this muscle group is heavily recruited has not yet been established. The only test of expiratory muscle force generating capacity presently available is maximum expiratory pressure (PEmax), but this is of limited value in the assessment of expiratory muscle fatigue since it is volitional. In a recent study changes of the centroid frequency of the abdominal muscle electromyogram (EMG) detected in normal subjects during threshold loading were suggestive of abdominal muscle fatigue. ${ }^{12}$ However, such EMG changes are not specific to fatigue. ${ }^{1314}$

Slowing of the MRR of skeletal muscle has been used as an early index of the onset of the fatiguing process ${ }^{15}$ and precedes failure of force generation. ${ }^{16}$ Based on previous studies using sniff oesophageal pressure (POES) and PDI to measure inspiratory muscle $M R R,{ }^{5-81617}$ we hypothesised that abdominal muscle MRR could be assessed from gastric pressure (PGA) traces obtained during a short sharp expiratory manoeuvre. To establish whether the technique was capable of detecting slowing of abdominal muscle MRR, we studied the effect of a two minute MIV on PGA MRR.

\section{Methods}

Five normal subjects familiar with respiratory manoeuvres and the purpose of the study were recruited. All were in good health and without respiratory disease. The study was approved by the local ethics committee.

Gastric pressure (PGA) and oesophageal pressure (POES) were measured using commercially available balloon tipped catheters, $110 \mathrm{~cm}$ in length (PK Morgan, Rainham, Kent, UK), positioned and tested in the standard manner. ${ }^{1819}$ Both catheters were connected to Validyne MP45-1 differential pressure transducers (range $\pm 200 \mathrm{~cm} \mathrm{H}_{2} \mathrm{O}$; Validyne Corporation, Northridge, California, USA). 
Transdiaphragmatic pressure (PDI) was defined as the difference between PGA and PoEs. All these pressure traces were displayed continuously during the study. Maximal isocapnic ventilation was performed with apparatus previously described. ${ }^{7}$ Briefly, the subject inhaled from a six litre anaesthetic bag supplied with an air $/ \mathrm{O}_{2} / \mathrm{CO}_{2}$ mixture. Inhaled gas composition and end tidal carbon dioxide tension $\left(\mathrm{PETCO}_{2}\right)$ were monitored with a Hewlett-Packard 78356A gas monitor (Hewlett-Packard Waltham, Massachusetts, USA). PeTCO $_{2}$ was maintained at $5.5 \pm 0.5 \mathrm{kPa}$ by adjustment of the inhaled carbon dioxide concentration. The inhaled oxygen concentration was kept at $22 \pm 2 \%$. Expiratory flow was measured with a Fleisch no. 4 pneumotachograph head (Fleisch, Lausanne, Switzerland) connected to a Mercury CS6 electrospirometer (Mercury Electronics, Glasgow, UK). All signals were digitised via a 12-bit NB-M10-16 (National Instruments, Austin, Texas, USA) analoguedigital converter and acquired into a Macintosh Quadra 700 computer (Apple Computer Inc, Cupertino, California, USA) running LabVIEW software (National Instruments, Austin, Texas, USA).

In order to assess whether the electrical activity of the abdominal muscles ceased at the point where PGA reached peak amplitude, we measured electromyographic (EMG) signals of the abdominal muscles in three subjects. Pairs of electrodes were placed lateral to the rectus muscle below the costal margin, medial to the inguinal ligament, and over the rectus muscle at the level of the umbilicus. Ground electrodes were placed close to the recording electrodes. The resulting signals were passed via long leads to a Magstim Neurosign 2000 preamplifier and amplifier (Magstim Company, Whitland, Dyfed, Wales) and displayed via a combined pressure and EMG recording programme based on LabView software with a recording frequency of $2 \mathrm{kHz}$.

To measure electrical activity of the diaphragm during expiratory manoeuvres we used an oesophageal electrode catheter in one subject. The catheter was positioned at the point of maximum EMG activity during sniffing and was fixed at the nose by tape.

STUDY PROTOCOL

All measurements were made with the subjects seated. They were asked to perform short sharp expiratory manoeuvres through a flanged mouthpiece, the distal end of which had a resistance created by a $3 \mathrm{~mm}$ orifice. A noseclip was worn. They were instructed to begin the manoeuvre at the end of a normal expiration. End expiratory PoEs was marked on the computer screen to help the subjects perform the manoeuvres from functional residual capacity (FRC). After a brief period of training, expiratory manoeuvres of different peak pressure amplitude were recorded. This broad range of baseline pressures allowed us to compare PGA MRR after MIV with baseline PGA MRR for the same peak pressure amplitude. Following the acquisition of baseline MRR data the subjects performed MIV for two minutes. All of them were familiar with the technique. They were asked to maintain the highest possible ventilation for as long as the run lasted. Throughout the run the subjects were vigorously encouraged verbally. No specific instructions were given about the tidal volume (VT), the duty cycle (TI/TTOT), or the respiratory frequency. PoEs, PGA, and expiratory flow were recorded throughout the run.

Pressure-time products were calculated as the product of mean pressure, inspiratory time, and respiratory rate. The beginning and the end of inspiration were determined from the flow signal. Inspiratory pressure-time product for transdiaphragmatic and oesophageal pressures were calculated from PDI and POES during inspiration. Expiratory pressure-time product for gastric pressure was calculated from PGA during expiration. PGA during expiration and PDI during inspiration were integrated from a baseline level taken as the resting end expiratory pressures before the MIV. ${ }^{20}$ PoES was integrated from zero pressure. ${ }^{20}$

Immediately after the MIV run, expiratory manoeuvres were performed from FRC every five seconds for five minutes and a further 10 expiratory manoeuvres were performed at 10 minutes. Subjects were instructed to avoid both very low or maximum efforts. PGA was recorded and MRR was calculated as the maximal rate of decay of pressure divided by peak pressure with units of $\%$ pressure loss $/ 10 \mathrm{~ms} .^{21-23}$ This normalisation of MRR allows a comparison of results deriving from pressure wave forms of different peak amplitude. ${ }^{21}$

MRR was obtained from PGA traces that satisfied the following criteria: (1) expiratory manoeuvre performed from FRC as judged by baseline POES immediately before the manoeuvre; (2) peak pressure maintained for less than $50 \mathrm{~ms}$; (3) total duration of the manoeuvre less than $600 \mathrm{~ms}$; and (4) pressure wave form of manoeuvre displaying smooth upstroke and decay curves. By these criteria $85 \%$ of expiratory manoeuvres were suitable for analysis.

Within-occasion reproducibility of maximum PGA MRR and PGA MRR derived from manoeuvres at $40-80 \%$ of the maximum effort was assessed from the baseline measurements. Day-to-day reproducibility was assessed by repeating at least 30 expiratory manoeuvres in three subjects on two separate days.

The slowing of the abdominal muscle relaxation rate was also investigated by stimulating the abdominal muscles of two subjects before and after a one minute MIV. A $90 \mathrm{~mm}$ circular coil powered by a Magstim Magnetic stimulator positioned over T10 was used. This technique has been previously described. ${ }^{24}$ The relaxation rate was measured from twitch PGA.

\section{DATA ANALYSIS}

Statistics were calculated using paired (Wilcoxon signed rank test) non-parametric test (Statview 4.0, Abacus Concepts Inc, Berkeley, California, USA). 
Table 1 Anthropometric data and vital capacity (VC)

\begin{tabular}{lllll}
\hline $\begin{array}{l}\text { Subject } \\
\text { no. }\end{array}$ & $\begin{array}{l}\text { Age } \\
\text { (years) }\end{array}$ & $\begin{array}{l}\text { Height } \\
(\mathrm{cm})\end{array}$ & $\begin{array}{l}\text { Weight } \\
(\mathrm{kg})\end{array}$ & $\begin{array}{l}\text { VC } \\
\text { (l) }\end{array}$ \\
\hline 1 & 41 & 186 & 82 & $6 \cdot 5$ \\
2 & 40 & 181 & 68 & $6 \cdot 2$ \\
3 & 43 & 182 & 79 & $5 \cdot 7$ \\
4 & 32 & 192 & 82 & $6 \cdot 8$ \\
5 & 28 & 178 & 75 & $6 \cdot 0$ \\
\hline
\end{tabular}

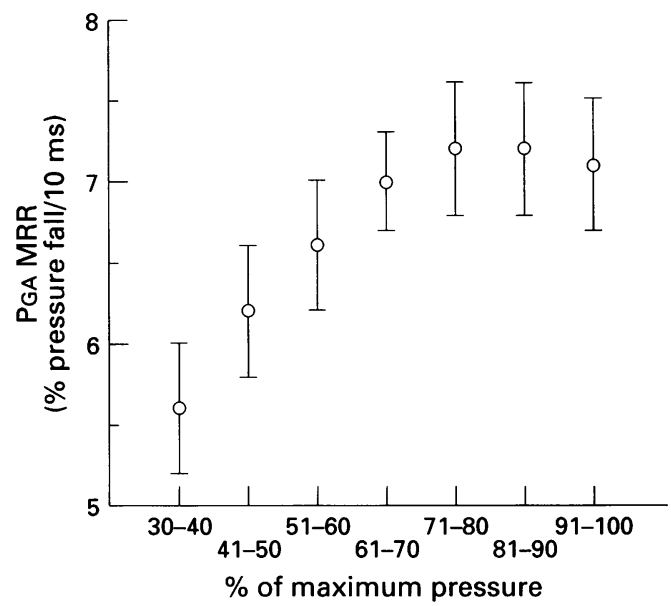

Figure 1 Mean (SE) PGA maximum relaxation rate $(M R R)$ for the five subjects over a wide range of pressure amplitudes.

\section{Results}

Anthropometric data and the vital capacity (VC) of the five subjects are shown in table 1 .

\section{BASELINE PGA MRR}

PGA MRR over a wide range of pressure amplitudes was obtained before MIV for each subject. As the peak pressure amplitude increased, a progressive increase in the MRR value was

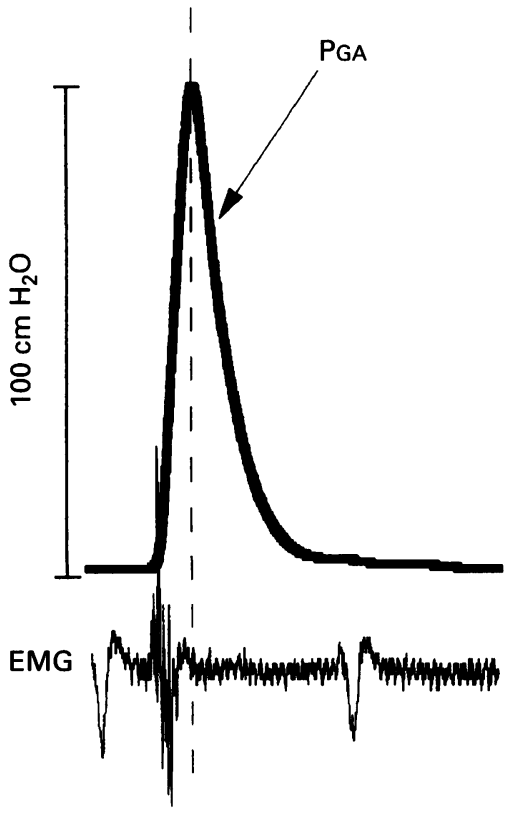

Before MIV
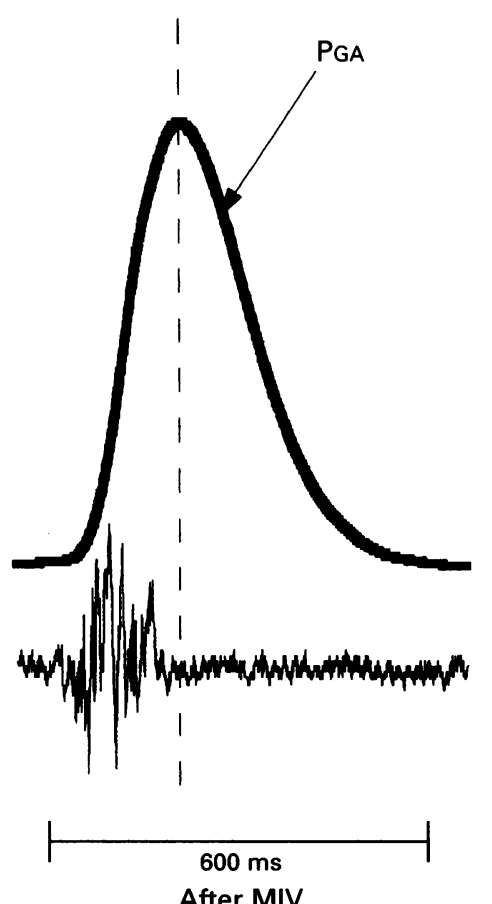

Figure 2 Gastric pressure traces of the same amplitude acquired before and after maximum isocapnic ventilation (MIV). The change in the slope of the decay curve is apparent on the trace on the right. EMG recordings from the external oblique muscle confirm that muscle activity ceases at the point where the pressure decay begins.
Table 2 Abdominal muscle maximum relaxation rate (MRR; expressed as \% fall in pressure $/ 10 \mathrm{~ms}$ ) before and after maximum isocapnic ventilation (MIV)

\begin{tabular}{llll}
\hline $\begin{array}{l}\text { Subject } \\
\text { no. }\end{array}$ & $\begin{array}{l}\text { Before } \\
\text { MIV }\end{array}$ & $\begin{array}{l}\text { After } \\
\text { MIV }\end{array}$ & $\begin{array}{l}\text { \% fall in } \\
\text { MRR }\end{array}$ \\
\hline 1 & $6 \cdot 08$ & $4 \cdot 32$ & 29 \\
2 & $6 \cdot 55$ & $4 \cdot 25$ & 35 \\
3 & $6 \cdot 29$ & $4 \cdot 17$ & 34 \\
4 & $6 \cdot 61$ & $4 \cdot 83$ & 27 \\
5 & $6 \cdot 23$ & $4 \cdot 69$ & 25 \\
Mean (SD) & $6.35(0 \cdot 22)$ & $4.45(0 \cdot 29)$ & $30(4 \cdot 42)$ \\
\hline
\end{tabular}

observed (fig 1). Mean (SD) maximum PGA for the five subjects was $204(32 \cdot 5) \mathrm{cm} \mathrm{H}_{2} \mathrm{O}$ and mean (SD) maximum PGA MRR was $7 \cdot 1(0 \cdot 8) \%$ peak pressure fall $/ 10 \mathrm{~ms}$. Mean within-occasion coefficient of variation (CV) for maximum PGA MRR as assessed in five subjects for 35 measurements was $5 \cdot 17 \%$ (range $1 \cdot 9-9 \cdot 8 \%$ ) and for PGA MRR derived from 238 efforts at $40-80 \%$ of maximum was $8 \cdot 42 \%$ (range $4 \cdot 22-10 \cdot 35 \%$ ). Day-to-day CV assessed in three subjects on two different days was $2 \%$ (range $0 \cdot 5-3 \cdot 64 \%$ ).

\section{MRR CHANGES}

Figure 2 shows gastric pressure traces obtained during expiratory manoeuvres before and immediately after MIV. EMGs from surface electrodes are also illustrated. Immediately after muscle loading MRR slowed, returning to normal values within 5-10 minutes after MIV. The electrical activity of the expiratory muscles, as judged by the surface EMG recordings, ceased at the point of peak pressure amplitude. Mean PGA for the five subjects for the first recording following $\mathrm{MIV}$ was $99 \mathrm{~cm} \mathrm{H}_{2} \mathrm{O}$ (range 77-107). To compare PGA MRR before and after MIV 10-20 pressure traces were selected from the baseline traces of each subject to match in amplitude with the traces acquired after MIV. Mean baseline PGA for the first recording was $100 \mathrm{~cm} \mathrm{H}_{2} \mathrm{O}$ (range 76-107). Table 2 shows baseline PGA MRR for the five subjects and PGA MRR immediately after MIV. PGA MRR fell by $30 \%$ (range $25-35 \%)(p<0 \cdot 05)$. Figure 3 shows the time course of recovery of PGA MRR.

\section{MAXIMUM ISOCAPNIC VENTILATION}

The high ventilation, high PGA during expiration, high POES and PDI during inspiration observed at the beginning of the run gradually declined and reached a plateau after one minute. The decline in ventilation and in the PGA pressure-time product during expiration, and the decline in PoEs and PDI pressure-time products plotted against time are shown in fig 4 .

SLOWING OF MRR FROM ABDOMINAL MUSCLE TWITCHES

PGA MRR measured from stimulated contractions of the abdominal muscles slowed following MIV. Mean (SD) baseline TwPGA MRR for subject 2 was $6.3(0.7)$ and for subject 4 was $5 \cdot 4(0 \cdot 6)$. Following MIV, TwPGA MRR was $4 \cdot 6(0 \cdot 2)$ and $4 \cdot 4(0 \cdot 2)$, respectively. 


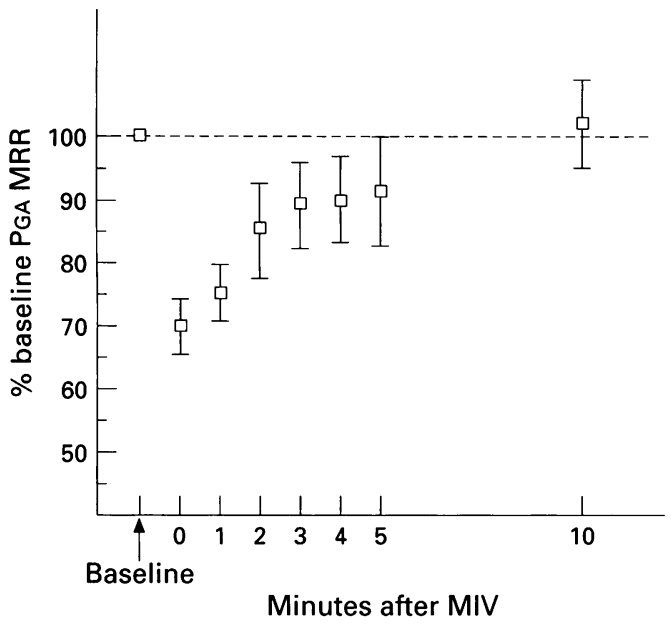

Figure 3 Mean (SD) PGA maximum relaxation rate (MRR) for the five subjects expressed as percentage of baseline immediately after maximum isocapnic ventilation (MIV) and at each minute thereafter. The time course of recovery shown on this graph is typical for skeletal muscles.

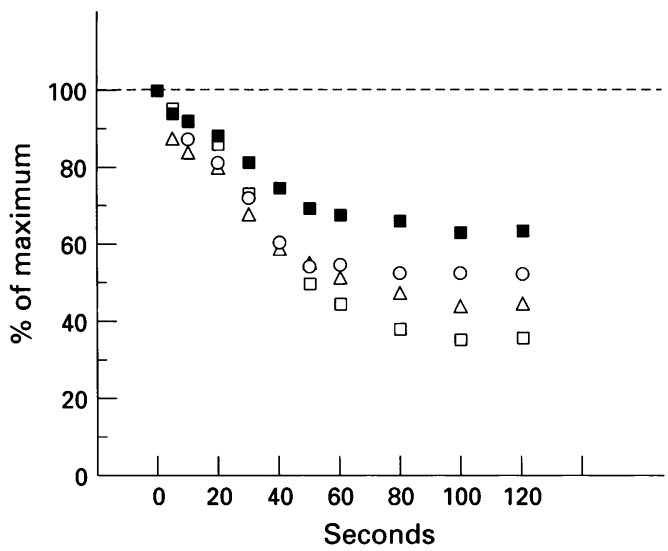

Figure 4 Decline in ventilation ( $\square$ ) and pressure-time product for gastric ( $\square$ ), oesophageal (O), and transdiaphragmatic $(\triangle)$ pressure traces presented as the percentage drop of the maximum performance during the initial 4-5 breaths.

\section{Discussion}

We have described a technique to measure the relaxation rate of abdominal muscles and have investigated whether the MRR of abdominal muscles changes after MIV.

During a dynamic inspiratory manoeuvre such as sniff, the inspiratory muscles contract for a short period of time and then become electrically silent as judged by EMG recordings. ${ }^{56}$ At this point the relaxation phase of the contraction begins and the tension decline is reflected in the pressure decay curve. The assumption that the MRR of the inspiratory muscles can be measured from respiratory pressures is based on the observation that the MRR of the inspiratory muscles is numerically similar to limb muscle, slows with exhaustive inspiratory loading, and recovers with the expected time course. ${ }^{5-816172526}$ To measure MRR of the expiratory muscles we developed a manoeuvre which requires a vigorous brief contraction of the abdominal muscles. Subjects were asked to perform a short sharp expiratory manoeuvre against an orifice.
This is accompanied by some flow and a small volume change. During this expiratory manoeuvre four abdominal muscles are contracting and then relaxing - namely, rectus abdominis, external and internal oblique, and transversus abdominis. The MRR of the expiratory muscles obtained by this method was very similar numerically to inspiratory muscle MRR from a sniff $^{5}$ and quadriceps MRR from a stimulated or voluntary contraction. ${ }^{21}$

Several factors other than fatigue can affect the relaxation rate and these require careful consideration. MRR is dependent on the peak tension developed during a voluntary contraction. ${ }^{23}$ To compensate for this, MRR is divided by peak pressure amplitude and expressed as \% pressure drop/10 ms. ${ }^{21}$ Nevertheless, despite normalisation, MRR increases with force during voluntary contractions as a result of progressive recruitment of fast twitch fibres. ${ }^{21}$ A previous study investigated the relationship of inspiratory muscle MRR with sniff peak pressure amplitude and found that MRR became progressively faster as pressure amplitude increased, especially up to $60 \%$ of maximum. ${ }^{27}$ We also found that abdominal muscle MRR measured from an expiratory manoeuvre progressively increases, and that this increase starts plateauing after the expiratory pressures reach $60 \%$ of maximum. Furthermore, after respiratory muscle loading the pressure amplitude of maximum voluntary contractions usually decreases. ${ }^{7817}$ To avoid the peak tension factor that can potentially affect MRR in addition to fatigue, we compared MRR of expiratory pressure traces of the same amplitude obtained before and after muscle loading.

Muscle length can also affect relaxation rate. ${ }^{26}$ Abdominal muscles can change length with changes in lung volume because they have attachments to the lower ribs. However, lung volume changes are unlikely to be important in the present study. Care was taken to perform expiratory manoeuvres from the end of expiration and from the same baseline oesophageal pressure. Furthermore, in a previous study in which a two minute MIV was used to load inspiratory muscles, magnetometer traces indicated that end expiratory lung volume did not alter significantly during the run. ${ }^{7}$ Muscle length could change during the expiratory manoeuvre because of gas compression and changes in lung volume due to flow through the $3 \mathrm{~mm}$ orifice. However, any influence of volume change during the manoeuvre would be of equal magnitude before and after MIV and thus would not account for any change of MRR.

Expiratory muscle activity persisting into the decay phase of PGA could decrease the rate of fall in pressure, causing an apparent slowing of the relaxation rate. However, the abdominal EMG recordings showed that the electrical activity of these muscles stopped at the peak pressure point. This was true both before and after MIV. Surface electrode measurements underestimate the activity of the deep abdominal muscle layer during respiration - the activity of the transversus abdominis ${ }^{28}-$ which is the most prominent expiratory muscle in 
man. Nevertheless, during volitional expiratory manoeuvres the transversus abdominis muscle acts synchronously with the other abdominal muscles. ${ }^{28}$ The electrical activity of the superficial muscle layer can therefore be used to assess the beginning and the end of the activity of all four abdominal muscles with reasonable accuracy.

With the method we used some activity of the abdominal muscles could go undetected because of the background noise of the EMG signal. Nevertheless, we could detect EMG activity produced by expiratory efforts creating gastric pressures as low as $6-8 \mathrm{~cm} \mathrm{H}_{2} \mathrm{O}$. We believe that, even if a sustained muscle contraction had taken place during the relaxation phase, it would have been of such magnitude that it could not seriously affect our results. This is also supported by the observation that the abdominal muscle relaxation rate measured from stimulated contractions slows following MIV.

Diaphragmatic activity could affect abdominal muscle MRR measurements if it generated gastric pressure during the relaxation phase of the abdominal muscles. This could happen only if contraction of the diaphragm was accompanied by a simultaneous downwards displacement. "Stiffening" of the diaphragm during the expiratory manoeuvre without any downwards displacement will only contribute to a poor transmission of gastric pressure in the thoracic cavity and therefore to PDI generation. Mean PDI for the five subjects during the baseline expiratory manoeuvres was $40.4 \mathrm{~cm} \mathrm{H}_{2} \mathrm{O}$ (range 31-62). Two possible mechanisms could explain this poor transmission of gastric pressure into the thoracic cavity during the manoeuvre: the "inspiratory" action of the abdominal muscles on the lower rib cage and/or the simultaneous activation of the diaphragm. During contraction of abdominal muscles the rise in abdominal pressure is transmitted to the lower rib cage at the zone of apposition resulting in an inflationary action. ${ }^{2930}$ Furthermore, the diaphragm is forced cranially and stretched, and this passive diaphragmatic tension tends to raise the lower ribs in a way similar to that seen during active diaphragmatic contraction. ${ }^{29}$ We do not know how much this mechanism could account for the observed PDI during the manoeuvre. In three patients with bilateral paralysis of the diaphragm assessed by magnetic and electrical stimulation of the phrenic nerves who performed the expiratory manoeuvre, PDI was observed but it was considerably less than the PDI observed in our subjects. ${ }^{31}$ The observation that the PDI generated during the expiratory manoeuvre was less in patients with bilateral paralysis of the diaphragm suggests that some activation of the diaphragm could also take place during this manoeuvre and contribute to the poor transmission of the gastric pressure to the thorax. This is not surprising as it has previously been shown that there is diaphragmatic EMG activity during cough and dynamic expiratory manoeuvres. ${ }^{32} 33$ We measured the EMG of the diaphragm during the expiratory manoeuvre in one subject and ob- served that the diaphragm was active during the abdominal muscle contraction phase. During the relaxation phase the diaphragm was almost silent and could not therefore contribute to any pressure generation.

In this study the pressure-time product during MIV of gastric, oesophageal, and transdiaphragmatic pressures are similar to those described in a previous study. ${ }^{20}$ We also found a strikingly high expiratory gastric pressuretime product during expiration, which showed a bigger drop than the oesophageal and transdiaphragmatic pressure-time products. During MIV vigorous abdominal muscle contraction is necessary to overcome the high airway resistance of rapid expiratory flow rates and to decrease expiratory time to achieve high breathing frequencies. ${ }^{34} \mathrm{It}$ is probable that contraction of abdominal muscles could also contribute to inspiratory muscle performance by optimising diaphragm function by lengthening muscle fibres. ${ }^{356}$ Inspiration during MIV begins from a low lung volume so part of the inspiratory work of breathing is shared by expiratory muscles. During MIV the highest level of ventilation cannot be sustained for long. ${ }^{7037}$ The rapid decline of ventilation and inspiratory pressures has recently been shown to occur in parallel with a slowing of the MRR of the inspiratory muscles. ${ }^{7}$ We have shown that the substantial decline in ventilation and pressure generation observed during MIV is also associated with slowing of expiratory muscle MRR. This implies that abdominal muscle fatigue may contribute to the decline in performance observed during MIV.

We conclude that the MRR of abdominal muscles measured from gastric pressure is similar to that described for the diaphragm and other skeletal muscles. During MIV the expiratory muscles are excessively loaded and show signs of fatigue, as judged by the slowing of their relaxation rate. The time course of recovery of PGA MRR is similar to that for other skeletal muscles.

The authors would like to thank Domingos Da Silva of the Biomedical Engineering Department of the Royal Brompton Hospital for his technical support and his help with the construction of some of the equipment used in this study.

Dr Kyroussis is supported by a grant from the State Scholarship Foundation of Greece (SSF/IKY).

1 Campbell EJM. An electromyographic study of the role of abdominal muscles in breathing. F Physiol 1952;117: 222-33.

2 De Troyer A, Ninane V, Gilmartin JJ, Lemerre C, Estenne MJ. Triangularis sterni muscle use in supine humans. $\mathscr{f}$ Appl Physiol 1987;62:919-25.

3 Martin JG, De Troyer A. The behaviour of the abdominal muscles during inspiratory mechanical loading. Respir Physiol 1982;50:63-73.

4 De Troyer A. Mechanical action of the abdominal muscles. Bull Eur Physiopathol Respir 1983;19:575-81.

5 Esau SA, Bye PTP, Pardy RL. Changes in rate of relaxation of sniffs with diaphragmatic fatigue in humans. $\mathcal{f} A p p l$ Physiol 1983;55:731-5.

6 Koulouris N, Vianna LG, Mulvey DA, Green M, Moxham $J$. Maximal relaxation rates of esophageal, nose, and mouth pressures during a sniff reflect inspiratory muscle fatigue. Am Rev Respir Dis 1989;139:1213-7.

7 Mulvey DA, Koulouris NG, Elliott MW, Laroche CM, Moxham J, Green M. Inspiratory muscle relaxation rate Moxham J, Green M. Inspiratory muscle relaxation rate after voluntary maximal isocapn

8 Kyopl Physiol 1991;70:2173-80. $\mathrm{CH}$ W/age S, Road J Green M, et al. Inspiratory muscle relaxation rate assessed Green $M$, et al. Inspiratory muscle relaxation rate ass
from sniff nasal pressure. Thorax 1994;49:1127-33.

9 Goldstone JG, Green M, Moxham J. Maximum relaxation rate of the diaphragm during weaning from mechanical rate of the diaphragm during wean
ventilation. Thorax 1994;49:54-60. 
10 Potter WA, Olafsson S, Hyatt E. Ventilatory mechanics and expiratory flow limitation during exercise in patients with obstructive lung disease. 7 Clin Invest 1971;50:910-9.

11 Dodd DS, Brancatisano T, Engel LA. Chest wall mechanics during exercise in patients with severe chronic air flow obstruction. Am Rev Respir Dis 1984;129:33-8.

12 Susuki S, Suzuki J, Ishii T, Akahori T, Okubo T. Relationship of respiratory effort sensation to expiratory muscle fatigue during expiratory threshold loading. $\mathrm{Am}$ muscle fatigue during expiratory
Rev Respir Dis 1992;145:461-5.

13 Moxham J, Edwards RH, Aubier M, De-Troyer A, Farkas G, Macklem PT, et al. Changes in EMG power spectrum (high-to-low ratio) with force fatigue in humans. $f \mathrm{Appl}$ Physiol 1982;53:1094-9.

14 Bazzy AR, Korten B, Haddad GG. Increase in electromyogram low-frequency power in nonfatigued contracting skeletal muscle. F Appl Physiol 1986;61:1012-7.

15 Edwards RHT, Hill DK, Jones DA. Metabolic changes associated with the slowing of relaxation in fatigued mouse muscle. F Physiol 1975;251:287-301.

16 Esau SA, Bellemare F, Grassino A, Permutt S, Roussos C, Pardy RL. Changes in relaxation rate with diaphragmatic Pardy RL. Changes in relaxation rate with diaphragm

17 Mador MJ, Kufel TJ. Effect of inspiratory muscle fatigue on inspiratory muscle relaxation rate in healthy subjects. 102:1767-73.

18 Milic-Emili J, Mead J, Turner JM, Glauser EM. Improved technique for estimating pleural pressure from esophageal balloons. $\mathcal{F}$ Appl Physiol 1964;19:207-11.

19 Baydur A, Behrakis PK, Zin WA, Jaeger M, Milic-Emili J. A simple method of assessing the validity of the esophageal balloon technique. Am Rev Respir Dis 1982;126:788-91.

20 Bai TR, Rabinovitch BJ, Pardy RL. Near maximal voluntary hyperpnea and ve

21 Wiles CM, Young A, Jones DA, Edwards RHT. Relaxation rate of constituent muscle-fibre types in human quadrate of constituent muscle-fibre

22 Edwards RHT, Hill DK, Jones DA. Metabolic changes associated with the slowing of relaxation in fatigued mouse muscle. F Physiol 1975;251:287-301.

23 Jewell BR, Wilkie DR. The mechanical properties of relaxing muscle. F Physiol 1960;152:30-47.

24 Kyroussis D, Mills G, Polkey MI, Hamnegard CH, Kolouris N, Green M, Moxham J. Abdominal muscle fatigue fol- lowing maximum ventilation in man. $\mathcal{F}$ Appl Physiol 1996 (in press).

25 Mulvey DA, Elliott MW, Koulouris NG, Carroll MP, Moxham J, Green M. Sniff esophageal and nasopharyngeal pressures and maximal relaxation rates in patients with respiratory dysfunction. Am Rev Respir Dis 1991;143. 950-3.

26 Levy RD, Esau SA, Bye PTP, Pardy RL. Relaxation rate of mouth pressure with sniffs at rest and with inspiratory mouth pressure with sniffs at rest and with inspirator

27 Mulvey D, Koulouris N, Elliott M, Moxham J, Green M. Maximal relaxation rate of inspiratory muscle can be effort-dependent and reflect the activation of fast-twitch fibers. Am Rev Respir Dis 1991;144:803-6.

28 De Troyer A, Estenne M, Ninane V, Van Gansbeke D, Gorini M. Transversus abdominis muscle function in humans. F Appl Physiol 1990;68:1010-6.

29 De Troyer A, Sampson M, Sigrist S, Kelly S. How the abdominal muscles act on the rib cage. $f$ Appl Physiol 1983;54:465-9.

30 Mier A, Brophy C, Estenne M, Moxham J, Green M, De Troyer A. Action of abdominal muscles on rib cage in Troyer A. Action of abdominal muscles
humans. $\mathcal{f}$ Appl Physiol 1985;58:1438-43.

31 Mills GH, Kyroussis D, Hamnegard CH, Wragg S, Moxham J, Green M. Chest wall activation during cervical magnetic stimulation does not produce inspiratory pressures. $A m \mathcal{F}$ Respir Crit Care Med 1995;151:A414.

32 Melissinos CG, Bruce EN, Goldman MD, Elliot E, Mead J. Pattern of diaphragmatic activity during forced expiratory vital capacity. $\mathcal{f}$ Appl Physiol 1981;51:1515-25.

33 Melissinos CG, Leith D. Pleural pressure in voluntary and spontaneous cough. Bull Eur Physiopathol Respir 1987; 12(Suppl):410S.

34 Ogilvie CM, Stone RW, Marshall R. The mechanics of breathing during the maximum breathing capacity test. Clin Sci 1955;14:101-7.

35 Grassino A, Goldman MD, Mead J, Sears TA. Mechanics of the human diaphragm during voluntary contractions.

36 Gandevia SC, Gorman RB, McKenzie DK, Southon FCG. Dynamic changes in human diaphragm length: maximal inspiratory and expulsive efforts studied with sequential radiography. F Physiol 1992;457:167-76.

37 Freedman $S$. Sustained maximum voluntary ventilation. Respir Physiol 1970;8:230-44. 